\title{
РЕКОМЕНДАЦИИ ПО ФОРМИРОВАНИЮ РОССИЙСКОЙ ОТРАСЛИ ПО ОБРАЩЕНИЮ С ОТХОДАМИ С УЧЕТОМ ПРИНЦИПА «З R»
}

\author{
(c) 2019 Васильева Оксана Николаевна \\ кандидат юридических наук, \\ доцент Департамента правового регулирования экономической деятельности \\ Финансовый университет при Правительстве Российской Федерации, Россия, Москва \\ E-mail: onvasilieva@fa.ru
}

(c) 2019 Журавлев Михаил Дмитриевич

студент группы ТЭК 4-3 Факультета экономики и финансов топливно-энергетического комплекса Финансовый университет при Правительстве Российской Федерации, Россия, Москва

E-mail: zhuravlev.mikhail.99@mail.ru

Статья подготовлена по результатам научно-исследовательской работы, выполняемой в рамках государственного задания в ФГОБУ ВО «Финансовый университет при Правительстве Российской Федерации» на 2019 год. В статье проведен анализ государственной политики в области обращения с отходами производства. Разработаны рекомендации по формированию отечественной отрасли по обращению с отходами с учетом мирового принципа управления отходами «3 R».

Ключевые слова: производственные отходы, принции «3 R», экология, повторное использование ресурсов

Мировая промышленность развивается стремительными шагами, производя и перерабатывая с каждым годом все больше ресурсов. В результате, вместе с производством растет количество отходов, а значительная часть ресурсов безвозвратно выбрасывается в окружающую среду, загрязняя ее и делая непригодной для жизни. Неэффективное использование природных ресурсов ведет к истощению запасов полезных ископаемых и глобальным экологическим проблемам. В дальнейшем ситуация станет более проблемной, так как население планеты растет с каждым годом, и, соответственно, производственные мощности будут увеличиваться вместе с количеством производственных отходов.

Огромное количество производственных отходов возникает вследствие низкого коэффициента использования ресурсов. В пример можно привести переработку металлической руды. Выход полезной продукции в среднем из горной массы при переработке металлических руд составляет только 2\% [1]. В мировом производстве задействуется больше ресурсов, чем природа способна восстанавливать. Неэффективные производство и управление отходами влекут за собой экологическую катастрофу. Поэтому вопрос грамотного управления отходами производства является одним из наиболее актуальных на сегодняшний день.
Современные тенденции «мусорного менеджмента» диктуются мировым принципом управления отходами «3R». В 2004 году на саммите G8 японский премьер-министр Дзуинтиро Коидзуми выдвинул «Инициативу 3R» [2]. Данная инициатива 3R расшифровывается как три ключевых направления мирового управления отходами:

- Reduce - снижение уровня отходов.

- Reuse - повторное использование.

- Recycle - использование вторичных ресурсов.

Мировое сообщество благоприятно приняло «Инициативу 3R». Для ее реализации необходимо принять и соблюдать следующие меры:

- Сокращение объема накопленных отходов и повышение эффективности использования ресурсов.

- Укрепление международных отношений в сфере управления отходами для усиления контроля за передвижением отходов через границы государств, а также формирование достоверной информации о количестве отходов в мире.

- Разработка более совершенного законодательства в целях повышения качества управления отходами.

- Применение новых технологий в рамках «Инициативы 3R».

$\mathrm{B}$ реализации программы 3R важную роль 
играют все участники производственного процесса и государство, а также научно-исследовательские организации, некоммерческие организации и потребители. Улучшить ситуацию по обращению с отходами можно только общими усилиями. Для этого необходимо создать единую общественную саморегулирующуюся систему, в которой недобросовестные производители или отдельные административные ресурсы будут исключаться из данной системы, либо к ним будут применяться санкции.

Для Российской Федерации проблема управления производственными отходами является одной из наиболее существенных. По данным Росприроднадзора, к началу 2018 года в России было накоплено 38 млрд. 73 млн. т. промышленных и бытовых отходов. При этом в течение 2017 года образовалось 6 млрд. 220,6 млн. т. (на 12,5\% больше, чем в 2016 году). Утилизировано для повторного применения в 2018 году было 2 млрд. 53,9 млн. т. отходов. Порядка 90\% приходится на долю различных производств, в основном добывающих (рисунок 1) [3].

Доля производственных отходов (90\%) является основной составляющей всех отходов производства. При этом доля отходов от добычи полезных ископаемых от общего количества производственных отходов в 2005 году занимала $82,5 \%$, а в 2015 году $92 \%$. Доля отходов от добычи топливно-энергетических полезных ископаемых выросла почти на 7\%, а остальных ископаемых, соответственно, снизилась на 7\% (таблица 1).

Можно сделать вывод, что основным источ-

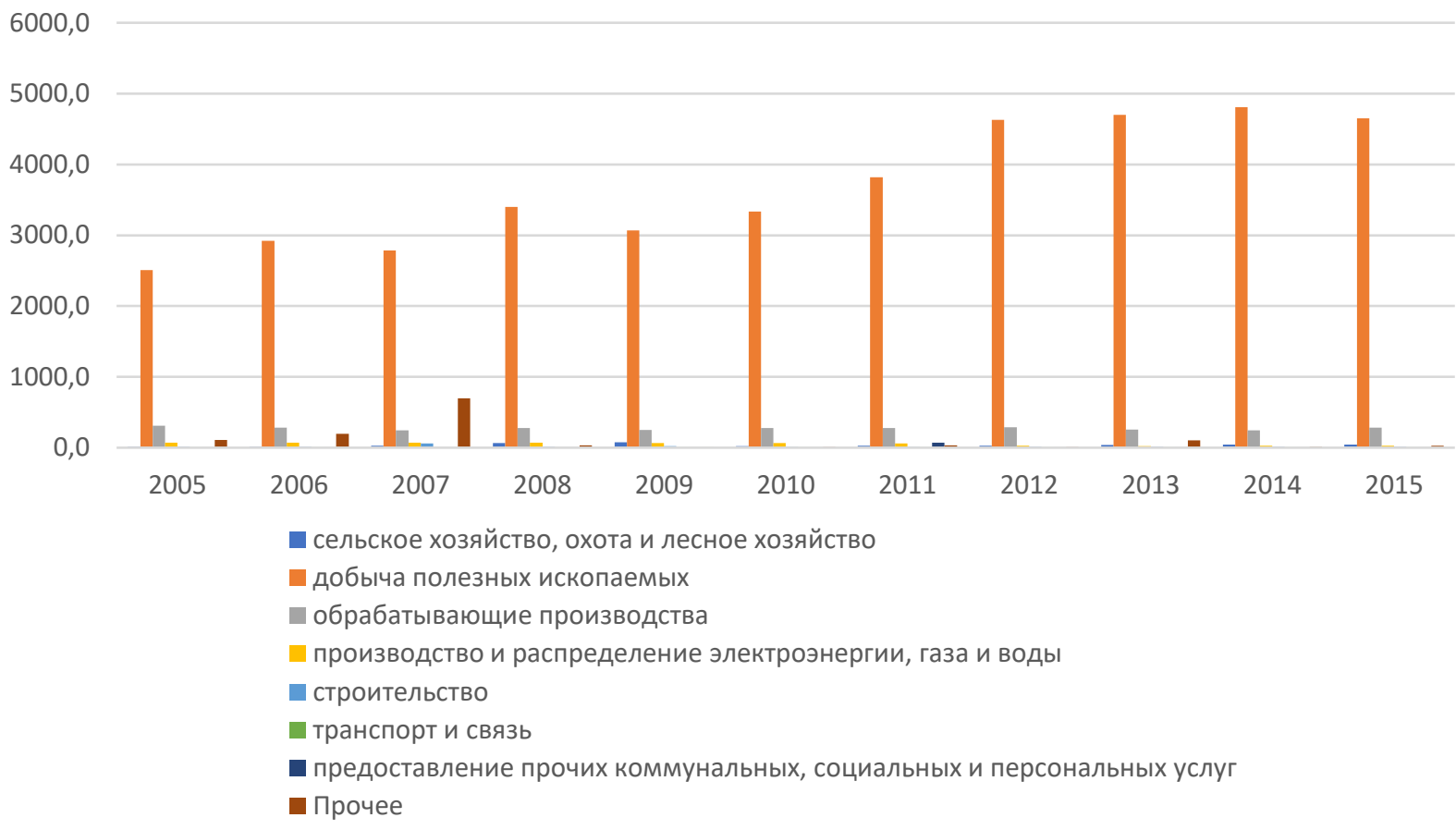

Рисунок 1. Образование отходов производства и потребления по видам экономической деятельности (млн. тонн) [4]

Таблица 1. Доли отходов добычи полезных ископаемых, в процентах от общего количества отходов.

\begin{tabular}{|l|c|c|}
\hline \multicolumn{1}{|c|}{ Наименование } & 2005 & 2015 \\
\hline Всего & $100 \%$ & $100 \%$ \\
\hline Добыча полезных ископаемых & $82,5 \%$ & $92 \%$ \\
\hline Из них: & & \\
\hline Добыча топливно-энергетических полезных ископаемых & $59,8 \%$ & $66,75 \%$ \\
\hline Добыча полезных ископаемых, кроме топливно-энергетических & $40,2 \%$ & $33,25 \%$ \\
\hline
\end{tabular}


ником производственных отходов является добывающая отрасль. Это можно объяснить несколькими причинами:

1. Устаревшее оборудование. Оборудование является важнейшим фактором, определяющим уровень отходов на производстве. Известно, что основные производственные фонды добывающих предприятий России формировались в СССР и являются крайне устаревшими как в техническом плане, так и в моральном. Оборудование не соответствует современным экологическим нормам, а выход полезной продукции в разы ниже, чем на зарубежных аналогах. Из этого вытекает огромное количество отходов по отношению к конечной продукции.

2. Недобросовестность производителей. Некоторые производители пренебрегают законодательством и утилизируют отходы производства ненадлежащим образом, например, организуют несанкционированные свалки или неправильно обращаются с опасными отходами, на многих предприятиях отсутствует первичная сортировка мусора, не применяется практика повторного использования ресурсов.

3. Несовершенное законодательство. Управление отходами производства в Российской Федерации регулируется Федеральным законом от 10.01.2002 N7-Ф3 (ред. от 27.12.2018) «Об охране окружающей среды» и Федеральным законом от 24.06.1998 N89-Ф3 (ред. от 25.12.2018) «Об отходах производства и потребления» и другими нормативно-правовыми актами. Однако, существующая правоприменительная практика не соответствует современным тенденциям по жесткому ограничению выбросов в атмосферу, нормам отходов на производстве, а также не имеет достаточно действенных санкций по отношению к нарушителям.

4. Сложность транспортировки производственных отходов. По всей территории РФ расположено большое количество добывающих предприятий, на которых образовываются производственные отходы. Поскольку территория России является крупнейшей в мире, а расстояние между свалками и мусороперерабатывающими заводами является труднопреодолимым и долгим, транспортировка отходов является дорогим мероприятием. Более того, затраты на транспортировку отходов с производства до мусороперерабатывающих центров могут превысить выгоду от повторного использования ресурсов, что делает принцип «3R» нерентабельным.
Проблема несанкционированных свалок является результатом неэффективного управления производственными отходами и бытового мусора. Под определение несанкционированной свалки попадают выброшенные в неположенных местах мусор и отходы и расположенные на территории 50 кв. м. и более и объемом 30 куб. м. и более [5]. Содержащиеся на несанкционированных свалках отходы содержат не только бытовой мусор (бумага, пластик, стекло и т.д.), но и опасные отходы (батарейки, аккумуляторы, ядовитые вещества, ртуть), которые должны утилизироваться специальными безопасными способами. Опасные отходы наносят экологический урон окружающей среде и могут стать причиной заражения земли, атмосферы и водных ресурсов. Более того, несанкционированные свалки являются прямой угрозой для жизни и здоровья человека.

В Российской Федерации статья 8.2 КоАП РФ «Несоблюдение экологических и санитарноэпидемиологических требований при обращении с отходами производства и потребления, веществами, разрушающими озоновый слой, или иными опасными веществами» привлекает к ответственности организаторов несанкционированных свалок. Наказанием является штраф до 250000 рублей для юридических лиц или административное приостановление их деятельности на срок до девяноста суток. Ответственными за решением проблемы несанкционированных свалок являются полиция и Росприроднадзор. Также, в мероприятиях по ликвидации должна принимать участие местная администрация. Однако, несмотря на принимаемые меры, количество несанкционированных свалок растет. Можно сделать вывод, что существующих мер недостаточно для решения данной проблемы. Необходимо принять следующие меры:

1. Привлечение населения и организаций для поиска несанкционированных свалок с помощью материального стимулирования. Для более эффективного поиска свалок необходимо материально стимулировать население, а также привлечь некоммерческие и природозащитные организации. Возможным решением может стать создание народных объединений по поиску и ликвидации свалок, которые будут поддерживаться местной администрацией.

2. Улучшение работы административных ресурсов. На сегодняшний день жителю, обнаружившему несанкционированную свалку, 
необходимо написать обращение в местную администрацию и Росприроднадзор, прикрепить фотографии и указать положение несанкционированной свалки на карте. На практике время реагирования может затянуться на долгий срок. Необходимо усовершенствование системы взаимосвязи между населением, местной администрацией и Росприроднадзором, а также максимальное упрощение системы оповещения о несанкционированных свалках.

3. Ужесточение наказания за организацию несанкционированных свалок. Необходимо увеличить размер штрафа. Максимальная сумма штрафа -250000 рублей. Справедливым решением будет являться введение прогрессивной шкалы штрафа, применяя повышающие коэффициенты в зависимости от прибыли организации. Например, для организаций с ежегодной прибылью до 1000000 рублей коэффициент 1, от 1000000 до 5000000 - коэффициент штрафа 2 и так далее.

Одна из современных мировых тенденций последних лет - цифровизация всех сфер деятельности, включая управление отходами. В России есть несколько программных продуктов в области отходов, которые выполняют различные функции: учет, управление, регулирование и анализ. В качестве примера можно привести следующие ПП:

- ПК «Отходы-регион». Используется в Вологодской и Тюменской областях. Предназначена для учета отходов и места их размещения, документарного управления и подготовки начальных данных по оплате размещения отходов.

- ПК «Региональный кадастр отходов». Используется в Магаданской области. Предназначена для сбора и обработки данных для ведения регионального кадастра отходов.

- ПК «Учет обращения с отходами». Используется в Краснодарском крае. Предназначена для сбора, учета и обработки данных в области управления отходами для юридических лиц и индивидуальных предпринимателей.

- ПП «1С: Предприятие 8. Производственная безопасность. Охрана окружающей среды». Используется во всех федеральных округах. Предназначена для автоматизации учета, планирования, контроля и отчетности в области управления с отходами на предприятиях.

Рассмотренные программы в большей степени решают задачи учета, чем регулирования или планирования управления отходами. Более того, данные ПП не имеют возможности обмена данными с другими программами, а также отсутствует возможность проверки предоставляемой информации об отходах. Еще одним минусом является отсутствие сообщения между административными ресурсами, населением и предприятием, а также платность программ.

В результате анализа проблемы обращения с производственными отходами в России можно сделать следующие выводы:

1. Опыт развитых стран по обращению с отходами и современные тенденции в этой сфере, в частности принцип «3R», не применяется в полной степени в России.

2. Основным источником производственных отходов является добывающая отрасль, в основном из-за устаревшего оборудования и отсутствием внедрения новых технологий.

3. Проблема несанкционированных свалок остается нерешенной на сегодняшний день и представляет угрозу для населения и окружающей среды.

4. Информационно-технологическая база по управлению отходами требует серьезных доработок, так как она не является одинаково эффективной для различных субъектов управления отходами.

Для разрешения ряда накопившихся проблем необходимо быстро и комплексно принимать решения, основываясь на опыте стран, преуспевших в менеджменте отходов. Усовершенствование системы управления требует не только капиталовложений, но и улучшения работы административного ресурса и контроль в частном секторе. Можно выделить основные направления, способствующие эффективному развитию отечественной отрасли управления отходами:

1. Обновление основных производственных фондов добывающих предприятий, внедрение новейших технологий безотходного производства и применение практики повторного использования ресурсов.

2. Модернизация функционирования административных ресурсов, а именно усиление контроля над производственными предприятиями в области отходов, ускорение времени реакции на нарушения и привлечение населения для обнаружения нарушений утилизации отходов, возможно создание отдельного органа, сосредоточенного непосредственно на решении проблем производственных отходов. 
3. Введение прогрессивного штрафа за нарушение обращения с отходами в зависимости от прибыли предприятия, установление четких нормативов количества отходов в каждом виде производства, опираясь на показатели новейшего оборудования по уровню отходов, выбросов в атмосферу и прочее. За превышение нормативов также необходимо ввести прогрессивные штрафы.

4. Создание единой информационной электронной базы, способной выполнять все главные операции в области управления отходами (учет, управление, планирование, регулирование и анализ). Необходимо создание единой электронной площадки управления отходами как для административных структур, так и для бизнеса в целях упрощения взаимодействия. Возможно применение технологий искусственного интеллекта.

\section{Библиографический список}

1. Манохин А.И., Резниченко В.А., Карязин И.А., Морозов А.А. Комплексное использование сырья фундаментальная основа замкнутого производства и интенсификации экономики // Комплексное использование минерального сырья. 1987. № 5.

2. Степанова С. А. Создание общества, ориентированного на ресурсосбережение. Инициатива 3R // Рециклинг отходов. 2001. № 6. С. 3-4.

3. https://tass.ru/info/6000776

4. Данные Росстата: http://www.gks.ru/wps/wcm/connect/rosstat_main/rosstat/ru/statistics/environment/\#

5. Постановление от 9 ноября 1999 года N1018 «Об утверждении Правил санитарного содержания территорий, организации уборки и обеспечения чистоты и порядка в г. Москве» 